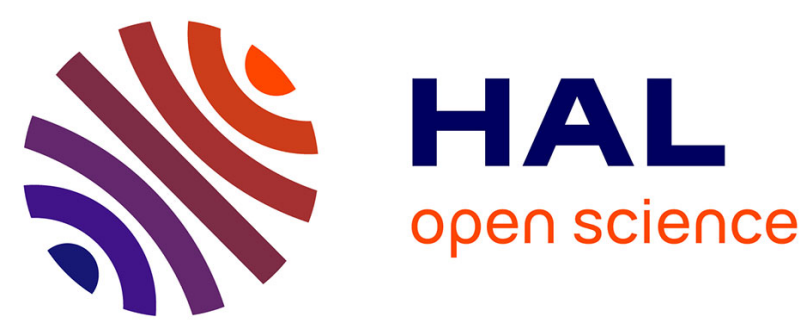

\title{
Modeling, Fabrication, and Characterization of Planar Inductors on YIG Substrates
}

\author{
Elias Haddad, Christian Martin, Charles Joubert, Bruno Allard, Maher \\ Soueidan, Mihai Lazar, Cyril Buttay, Béatrice Payet-Gervy
}

\section{To cite this version:}

Elias Haddad, Christian Martin, Charles Joubert, Bruno Allard, Maher Soueidan, et al.. Modeling, Fabrication, and Characterization of Planar Inductors on YIG Substrates. Advanced Materials Research, 2011, 324, pp.294-297. 10.4028/www.scientific.net/AMR.324.294 • hal-00672240

\section{HAL Id: hal-00672240 \\ https://hal.science/hal-00672240}

Submitted on 20 Feb 2012

HAL is a multi-disciplinary open access archive for the deposit and dissemination of scientific research documents, whether they are published or not. The documents may come from teaching and research institutions in France or abroad, or from public or private research centers.
L'archive ouverte pluridisciplinaire HAL, est destinée au dépôt et à la diffusion de documents scientifiques de niveau recherche, publiés ou non, émanant des établissements d'enseignement et de recherche français ou étrangers, des laboratoires publics ou privés. 


\title{
Modeling, Fabrication, and Characterization of Planar Inductors on YIG Substrates
}

\author{
Elias Haddad, a, Christian Martin ${ }^{1, b}$, Charles Joubert ${ }^{1, \mathrm{c}}$, Bruno Allard ${ }^{2, \mathrm{~d}}$, Maher \\ Soueidan ${ }^{2, e}$, Mihai Lazar ${ }^{2, \mathrm{f}}$, Cyril Buttay ${ }^{2, \mathrm{~g}}$, and Béatrice Payet-Gervy ${ }^{3, \mathrm{~h}}$ \\ ${ }^{1}$ University of Lyon, Ampere Lab, Lyon 1 University, CNRS, UMR5005, Lyon, F-69622, France \\ ${ }^{2}$ University of Lyon, Ampere Lab, INSA Lyon, CNRS, UMR5005, Villeurbanne, F-69621, France \\ ${ }^{3}$ University of Lyon, LT2C Lab, Jean Monnet University, Saint-Etienne, F-42023, France

 \\ dbruno.allard@insa-lyon.fr, ${ }^{\mathrm{e}}$ maher.soueidan@insa-lyon.fr, ${ }^{\mathrm{f}}$ mihai.lazar@insa-lyon.fr, \\ ${ }^{9}$ cyril.buttay@insa-lyon.fr, hbeatrice.payet@univ-st-etienne.fr
}

Keywords: Planar inductors, Magnetic material, DC-DC power conversion, Copper Electroplating, Passive components.

Abstract. This paper presents the design, fabrication, and characterization of micro planar inductors on a microwave magnetic material (YIG). Planar spiral inductors were designed for monolithic DCDC converters in System-In-Package with $100 \mathrm{MHz}$ switching frequency $\left(1 \mathrm{~W}, \mathrm{~V}_{\text {in }}=3.6 \mathrm{~V}, \mathrm{~V}_{\text {out }}=1\right.$ V). A microwave magnetic substrate (YIG) serves as mechanical support and also presents a double purpose by increasing inductance value and reducing electromagnetic perturbations. This last point seems to be a critical point to improve the good behavior of a switching mode power supply. In order to obtain the optimal design for the inductor, geometrical parameters were studied using Flux2D simulator and an optimized 30 to $40 \mathrm{nH}$ spiral inductor with expected $25 \mathrm{~m} \Omega \mathrm{R}_{\mathrm{DC}}, 3 \mathrm{~mm}^{2}$ surface area was designed. Subsequently, samples were fabricated by electroplating technique, and then tested using a vector network analyzer in the $10 \mathrm{MHz}$ to $100 \mathrm{MHz}$ frequency range. Results were then compared to the predicted response of simulated equivalent model.

\section{Introduction}

Passive components comprise the majority of chip area occupied by monolithic converters, even when the components are optimized for minimum area [1]. System-In-Package applications are facing miniaturization issues due to passive components size. The push towards higher and higher frequencies has generated much interest in novel structures for planar inductors. Therefore by increasing the switching frequency of DC-DC converters in the $10 \mathrm{MHz}$ and $100 \mathrm{MHz}$ frequency range, the size of filter passive components is dramatically reduced. Thus, the passive area of integration drops below the $10 \mathrm{~mm}^{2}$ range [2].

Planar devices offer several advantages. Some of these are better thermal management, low profile, and higher power densities. Although research on planar inductors is concentrated on integrating air core inductors on silicon wafers [3,4,5], the application of YIG substrates to planar inductors enables to increase the inductance without increasing the stray capacitance between the coils and the ground plane. In our application, surface area is the key point of designing the inductor since the aim is to integrate the inductor on the top of a SMPS die in a surface area of $3 \mathrm{~mm}^{2}$. We proposed a figure of merit $\left(\mathrm{MHz} / \mathrm{m} \Omega \cdot \mathrm{mm}^{2}\right)$ to evaluate our inductor performance targeting the DC/DC converter application. First, we describe the design issue based on Flux2D simulator. In the second part, fabrication process using electroplating technique will be detailed. And then, experimental results and micro-fabricated inductors are shown in the last section.

\section{Design and Simulation Results}

In order to obtain the optimal design and performance for the inductor, Flux2D software, a field solver based on finite elements has been used. A very accurate numerical solution may be obtained 
by using a three-dimensional finite-element simulator such as MagNet [6]. However, 3-D simulators are computationally intensive and require long run times, thus our model was studied in 2D using axial symmetric conditions as shown in Fig. 1(b). The aim of the simulations performed is to evaluate the impact of geometrical parameters of our structure on the inductance value and analyze frequency dependence of series resistance and inductance. As described in Fig. 1(a), the geometry characteristics of interest are the width of the strip $w$, the thickness of copper lines $t$, the number of turns $n$, the spacing between the turns $s$, and the inner diameter $d_{i}$. These parameters were evaluated with the spiral inductor surface area limited by $3 \mathrm{~mm}^{2}$ which is the key point in the design of the inductor since the aim is to integrate the inductor on top of a SMPS die.

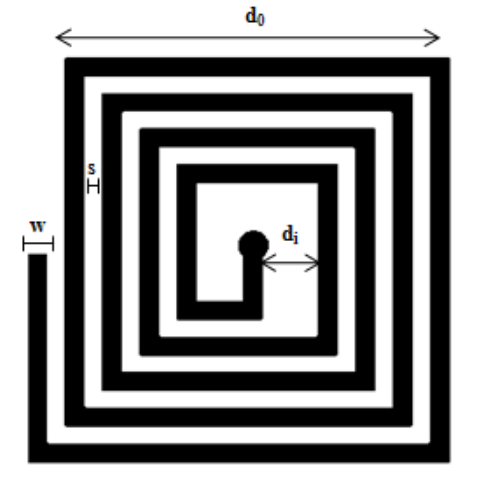

(a)

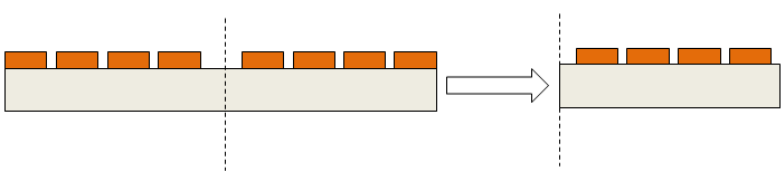

(b)

Fig. 1 (a) Spiral inductor geometry, (b) Cross section of the simulated inductor model

The inductor was designed on a magnetic material (YIG) with a relative magnetic permeability $\mu_{\mathrm{r}}=25$ [8] in our frequency range. In [7], it is demonstrated that capacitive effects between the turns of a spiral can be neglected up to $1 \mathrm{GHz}$. Skin effect is taken into consideration as it contributes to increasing series resistance of the inductor at high frequency. Since the inductor is designed for reducing current ripple, average current and resistance computed at low frequency are the main contributors to losses. In this condition, a specific Merit factor (Eq.1) taking in consideration DC resistance and inductance value was proposed to compare different models in our area of interest.

$$
\mathrm{IFM}=\frac{\mathrm{L}_{100 \mathrm{MHz}}(\mathrm{nH})}{\mathrm{R}_{\mathrm{DC}}(\mathrm{m} \Omega) \times \mathrm{S}\left(\mathrm{mm}^{2}\right)}
$$

\section{Simulations Guidelines}

Simulations have shown that:

- YIG doubles inductance value compared to an air core inductor with the same winding and reduces electromagnetic noise which interferes with other components on the die. Moreover, simulations have also shown that YIG thickness above $200 \mu \mathrm{m}$ has a slight effect on the inductance value.

- Copper thickness has a very small effect on inductance, but it contributes to a lower DC resistance.

- Increasing the space between the turns lowers the interwinding magnetic coupling, and thus decreases the inductance value.

- Widening the conductors reduces the inductance value, but it has an overall positive effect on Merit factor due to $\mathrm{R}_{\mathrm{DC}}$ decreasing more significantly.

- Inductance value increases with the number of turns, but Merit factor remains constant. This can be explained by the fact that improvement of IFM is slowed down by the increase of the series resistance.

- Narrowing the inner diameter implies increasing the negative magnetic coupling and hence lowering the inductance value. 
Simulations allowed us to evaluate our design with the optimal geometry contributing to the highest Merit factor with taking into consideration the limits of the fabrication process.

\section{Technological process}

Using the guidelines acquired through simulation analyses, we designed a planar spiral inductor of $3 \mathrm{~mm}^{2}$ surface area which was fabricated to target an inductance value of 30 to $40 \mathrm{nH}$ at $100 \mathrm{MHz}$ with $\mathrm{R}_{\mathrm{DC}}$ as low as possible. The inductors has four turns with $w=75 \mu \mathrm{m}, s=75 \mu \mathrm{m}, d_{i}=200 \mu \mathrm{m}$, and $t=50 \mu \mathrm{m}$.

Fabrication process is shown in Fig. 2. A seed layer Ti $500 \AA / \mathrm{Cu} 1500 \AA$ is deposited on the YIG substrate (a). Dry film photoresist is then laminated, and patterned (b). Next, copper lines are electroplated to mould photoresist patterns (c). Finally, the remaining dry film is removed and the seed layer is wet etched to isolate the coil turns (d).

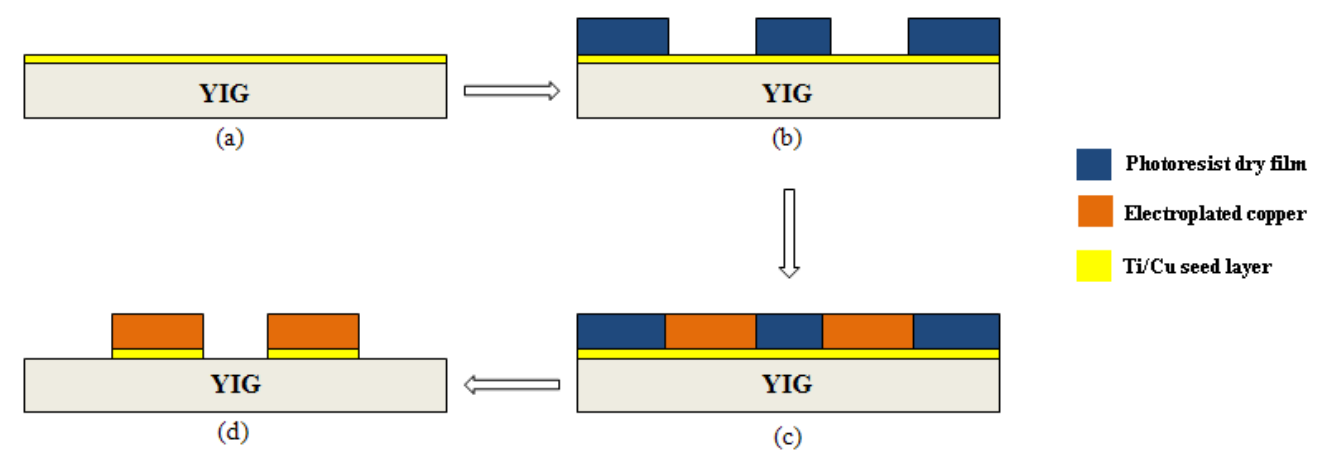

Fig. 2 Fabrication process of the spiral inductor

Copper electrodeposition is a low cost deposition technique that allowed us to achieve high aspect ratio: $75 \mu \mathrm{m}$ in width and $50 \mu \mathrm{m}$ in copper thickness at room temperature as shown in Fig. 3(a).

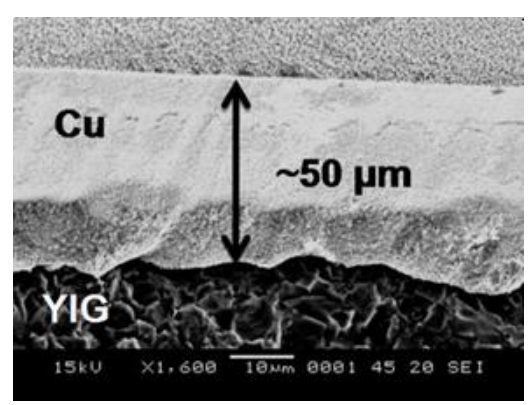

(a)

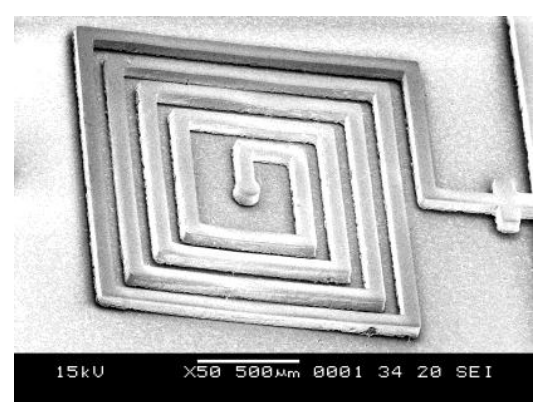

(b)

Fig. 3 SEM images of the micro-fabricated inductor

\section{Results and Discussion}

On-wafer device measurements have been carried out using Rohde \& Schwarz ZVA67 Vector Network Analyzer and Cascade Microtech Air Coplanar GSG probes from $10 \mathrm{MHz}$ to $1 \mathrm{GHz}$. Twoport scattering parameters (S-parameters) have been measured and then changed to admittance parameters (Y-parameters). Inductance $\mathrm{L}$ of the spiral inductor is subsequently extracted from the resultant $\mathrm{Y}_{11}$ parameters after the de-embedding procedure. Its expression is given as

$$
\mathrm{L}=\frac{1}{\frac{\operatorname{Imag}\left[\mathrm{Y}_{11}\right]}{2 \times \pi \times \text { Frequency }}} .
$$


Fig. 4 (a) shows the simulated and measured inductance from $10 \mathrm{MHz}$ to $1 \mathrm{GHz}$. We measured an inductance value of $35,78 \mathrm{nH}$ at $100 \mathrm{MHz}$. The slight difference between the simulated and measured inductance is due to the approximations applied in the simulation process. DC resistance was also measured using SMU. We determined a value of $20 \mathrm{~m} \Omega$ (Fig. 5). Merit factor corresponding to our application is equal to $0,6 \mathrm{nH} / \mathrm{m} \Omega \cdot \mathrm{mm}^{2}$.

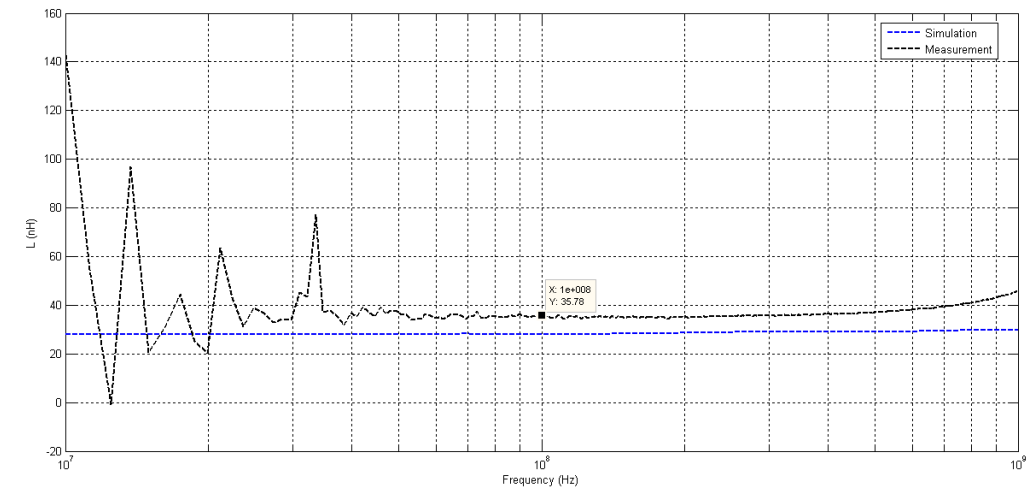

(a)

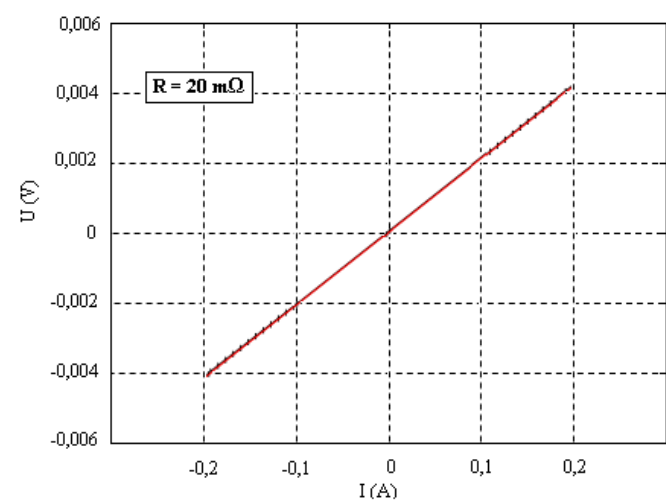

(b)

Fig. 4 (a) Measured and simulated inductance of the spiral inductor, (b) Measured DC resistance

\section{Summary}

In conclusion, planar spiral inductors were realized by electroplating technique. Electroplating copper lines on YIG substrate showed an improvement in the inductance value by a factor of 2 compared to an air core structure. We also reached a Merit factor of $0,6 \mathrm{nH} / \mathrm{m} \Omega . \mathrm{mm}^{2}$ which is a typical value for a planar inductor that will be integrated in a monolithic DC-DC converter with 100 $\mathrm{MHz}$ switching frequency.

\section{References}

[1] S. Musunuri, P. L. Chapman, Optimization issues for fully-integrated CMOS dc-dc converters, Proc. Conf. Record IEEE Industrial Applications Society Annu. Conf. (2002) 2405-2410.

[2] C. Martin, B. Allard, D. Tournier, M. Soueidan, J.-J. Rousseau, D. Allessem, L. Menager, V. Bley, J. -Y. Lembeye, Planar inductors for high frequency dc-dc converters using microwave magnetic material, IEEE ECCE. (2009) 1890-1894.

[3] B. Razavi: IEEE Journal Solid-State Circuits. Vol. 34 no. 3 (1999), 268.

[4] J. N. Burghartz, M. Soyuer, K. A. Jenkins: IEEE Trans. Electron Devices. Vol. 43 no. 9 (1996), 1559 .

[5] C. H. Ahn, M. G. Allen, Micromachined planar inductors on silicon wafers, IEEE Trans. on Indust. Electron. Vol. 45, no. 6 (1998).

[6] E. M. Freeman, MagNet 5 user guide: Using the MagNet version 5, Infolytica Corp., Montreal.

[7] C. P. Yue, S. S. Wong, Physical modeling of spiral inductors on silicon. IEEE Trans. Electron Dev. Vol. 47, no. 3, (2000) 560-568. 